\title{
Percutaneous left atrial appendage occlusion: New perspectives for the method
}

\author{
Iwona Gorczyca-Michta ${ }^{1}$, Beata Wożakowska-Kapłon ${ }^{1,2}$ \\ ${ }^{1} 1^{\text {st }}$ Clinic of Cardiology and Electrotherapy, Swietokrzyskie Cardiology Center, Kielce, Poland \\ ${ }^{2}$ Faculty of Medicine and Health Sciences, Jan Kochanowski University, Kielce, Poland
}

\begin{abstract}
Ischemic stroke is a common complication of atrial fibrillation $(A F)$. Currently, oral anticoagulant drugs are the most commonly used method of stroke prevention. Left atrial appendage occlusion is thought to be the main source of thrombi in patients with AF. Percutaneous left atrial appendage is a valuable therapeutic option for selected high-risk patients with $A F$ and contraindications for oral anticoagulation therapy. While complete closure of the left atrial appendage is the goal of a device implantation the variable nature of the left atrial appendage anatomy makes this goal difficult to achieve. Currently, there are several types of devices available for left atrial appendage occlusion. Since the first percutaneous left atrial appendage occlusion in 2002 many studies have investigated both the safety and efficacy of this therapy using different closure devices. Still unresolved issues include a lack of data on optimal patient selection, risk of complications, and anticoagulant treatment after left atrial appendage occlusion. (Cardiol J 2017; 24, 5: 554-562)
\end{abstract}

Key words: atrial fibrillation, left atrial appendage, thrombus, occlusion, contraindications to anticoagulant treatment

\section{Introduction}

Atrial fibrillation (AF) is the most common sustained arrhythmia, with an estimated prevalence of 6 million among all Europeans [1]. The most serious complication of AF are thromboembolic events, especially embolic stroke. Patients with AF have a fivefold higher risk of stroke and a twofold higher risk of all-cause mortality than patients without AF [2]. The annual stroke risk varies from $0.19 \%$ to $23 \%$, depending on patient risk factors (age, sex and co-morbidities) [3, 4]. Strokes in AF are associated with greater mortality and morbidity, more disability, longer hospital stays and lower rates of discharge to the patient's home [5]. According to the Framingham Study, patients with a history of stroke due to AF have $25 \%$ and $63 \%$ risks of dying within 30 days and within 1 year, respectively [6]. Substantially high mortality and morbidity rates emphasize the need for a highly effective stroke prevention.

\section{Anticoagulation therapy for stroke prevention}

Oral anticoagulant $(\mathrm{OAC})$ agents are essential for the prevention of stroke and thromboembolism in $\mathrm{AF}$ patients. Two ways of anticoagulation are currently available — vitamin K antagonists (VKA) and non-vitamin $\mathrm{K}$ oral anticoagulants (NOAC). VKA therapy reduces the risk of stroke by $64 \%$ and mortality by $26 \%$, as compared to aspirin or no therapy [7]. The use of VKA is limited by a narrow therapeutic interval, necessitating frequent monitoring and dose adjustments. It is estimated that only half of VKA-treated patients are within the therapeutic range of international normalized ratio (INR) [8]. The narrow therapeutic window of VKA leads to a delicate balance between a lack of efficacy and an increased risk of bleeding. NOAC, including the direct thrombin inhibitor dabigatran and factor $\mathrm{Xa}$ inhibitors apixaban, edoxaban and rivaroxaban, are increasingly used for stroke prevention in patients with $\mathrm{AF}$ as alternatives to VKA.

Address for correspondence: Iwona Gorczyca-Michta, $\mathrm{MD}, \mathrm{PhD}, \mathrm{1}^{\text {st }}$ Clinic Cardiology and Electrotherapy, Swietokrzyskie Cardiology Center, ul. Grunwaldzka 45, 25-736 Kielce, Poland, tel: +48 604407 956, e-mail: iwona.gorczyca@interia.pl 
Recently, four NOAC have been compared with warfarin in large randomized trials for the prevention of stroke and systemic embolism. Both VKA and NOAC are effective in preventing stroke and systemic embolism in AF. A meta-analysis based on high-dose treatment groups of the main studies of warfarin vs. NOAC included 42,411 patients receiving NOAC and 29,272 receiving warfarin (71,683 participants included in the RE-LY, ROCKET AF, ARISTOTLE, and ENGAGE AF-TIMI). NOAC at these doses significantly reduced the risk of stroke (RR 0.81; 95\% CI 0.73-0.91; p < 0.0001), which was mainly due to a reduction in hemorrhagic stroke (RR 0.49 ; 95\% CI 0.38-0.64; $\mathrm{p}<0.0001)$ and mortality (RR 0.90; 95\% CI 0.85-0.95; $\mathrm{p}=0.0003$ ), as compared to VKA. Intracranial hemorrhage was reduced by a half in patients randomized to the NOAC therapy (RR 0.48 ; 95\% CI $0.39-0.59$; $\mathrm{p}=0.0001$ ), while gastrointestinal bleeding events were more frequent in comparison to the VKA therapy (RR $1.25 ; 95 \%$ CI 1.01-1.55; $\mathrm{p}=0.04$ ) [9].

According to current guidelines, oral anticoagulation for prevention of stroke and systemic embolism are recommended in all male AF patients with a $\mathrm{CHA}_{2} \mathrm{DS}_{2}$-VASc score of 2 or more and in all female $\mathrm{AF}$ patients with a $\mathrm{CHA}_{2} \mathrm{DS}_{2}$-VASc score of 3 or more. Oral anticoagulation for prevention of thromboembolism should be considered in male AF patients with a $\mathrm{CHA}_{2} \mathrm{DS}_{2}$-VASc score of 1 and in female $\mathrm{AF}$ patients with a $\mathrm{CHA}_{2} \mathrm{DS}_{2}$-VASc score of 2 , considering individual characteristics and patient preferences [10]. When oral anticoagulation is initiated in a patient with non-valvular $\mathrm{AF}$ who is eligible for a NOAC, a NOAC is recommended in preference to a VKA.

\section{Indication to left atrial appendage closure}

The presence of absolute contraindications to anticoagulant treatment is a major limitation in the use of NOAC or VKA. Contraindications exclude certain patients from any form of anticoagulation treatment, because the probability of bleeding in this group of AF patients is very high. On the other hand, discontinuation of anticoagulation treatment in patients with a high risk of stroke is not recommended. For patients who are poor candidates for a long-term oral anticoagulation, percutaneous left atrial appendage occlusion (LAAO) is a devicebased alternative for stroke prophylaxis in AF.
European guidelines for the management of AF now recommend that percutaneous LAA closure may be considered in patients with a high risk of stroke who have contraindications to long-term oral anticoagulation (class IIb indication, level of evidence B) [10]. According to the guidelines, patients after intracranial bleeding during anticoagulant treatment are at a high risk of life-threatening bleeding. In this group of AF patients, LAAO may be considered (class IIb indication, level of evidence B) [10].

\section{Anatomy of left atrial appendage}

Echocardiographic, surgical and autopsy studies suggest that LAA is a major source of thromboembolism in patients with AF and a site for thrombus formation in $90 \%$ of patients with thromboembolic events in non-valvular AF patients [11-12]. Transesophageal echocardiography (TEE) is the main imaging modality used to assess LAA anatomy, aid in the selection of a suitable device and size, and identify anatomic contraindications. Two-dimensional and three-dimensional TEE is used in conjunction with fluoroscopy to guide the procedure and evaluate device placement. LAA is the remnant of the original embryonic left atrium, a tubular, blind-ended pouch attached to the main body of the left atrium. LAA consist of three parts: ostium, neck and lobar region (Table 1) [13]. Based on computed tomography and cardiac magnetic resonance, the shapes of LAA were classified into four morphological types (Table 2) [13-16]. Important aspects that should be considered before LAAO are correct sizing of the landing zone diameters for the selected device and the measurement of the depth, number and origin of additional lobes. Lobes are defined as protrusions from the main body with the tail portion also representing a lobe. It is estimated that $80 \%$ of LAAs have a multilobed anatomy. Veinot et al. [17] found that the occurrence of 2 (54\%) lobes was most common, followed by $3(23 \%)$ lobes, $1(20 \%)$ lobe and $4(3 \%)$ lobes. It was noted that there were no significant differences in LAA morphologies attributed to sex or age.

An increased number of lobes was associated with the presence of a thrombus independent of the clinical risk [18]. The "cauliflower" morphology is most often associated with embolic events. The risk of thrombus formation inside LAA during sinus rhythm and adequate blood flow is low. AF causes dysfunction and remodeling of LAA that predispose to low blood flow and thrombosis [19]. 
Table 1. Anatomy of left atrial appendage [13].

\begin{tabular}{llll}
\hline LAA region & The ostium & The neck & The lobar region \\
\hline $\begin{array}{l}\text { Anatomic } \\
\text { description }\end{array}$ & $\begin{array}{l}\text { Opening from } \\
\text { the LA to the LAA } \\
\text { Diameter } 10-40 \mathrm{~mm} \\
\text { Length } 16-51 \mathrm{~mm} \\
\begin{array}{l}\text { Volume } 0.7-19.2 \mathrm{~mL} \\
\text { Mitral value }\end{array}\end{array}$ & $\begin{array}{l}\text { The ostium opens to a neck } \\
\text { region which constitutes } \\
\text { a tubular junction between } \\
\text { the ostium and the lobar region }\end{array}$ & $\begin{array}{l}\text { Largest and most variable distal } \\
\text { part of the LAA }\end{array}$ \\
& $\begin{array}{l}\text { Left upper pulmonary } \\
\text { vein }\end{array}$ & $\begin{array}{l}\text { Circumflex coronary artery } \\
\text { Left anterior descending artery } \\
\text { Sinus node artery (1/3) }\end{array}$ & $\begin{array}{l}\text { The tip of the appendage } \\
\text { overlaps the base of the } \\
\text { pulmonary trunk, the left } \\
\text { coronary artery, or its anterior } \\
\text { branch and the great cardiac } \\
\text { vein at varying levels } \\
\text { The left phrenic nerve runs } \\
\text { along the pericardium } \\
\text { overlaying the LAA }\end{array}$ \\
\hline
\end{tabular}

LA — left atrium; LAA — left atrium appendage

Table 2. Morphological classification left atrial appendage [13-16].

\begin{tabular}{|c|c|c|c|c|}
\hline Type & Chicken wing & Cactus & Windsock & Cauliflower \\
\hline $\begin{array}{l}\text { Frequency } \\
\text { of occurrences }\end{array}$ & $48 \%$ & $30 \%$ & $19 \%$ & $3 \%$ \\
\hline Long of main lobe & $\begin{array}{l}>4 \mathrm{~cm} \\
\text { With a folded angle } \\
<100 \text { degrees }\end{array}$ & $\begin{array}{l}<4 \mathrm{~cm} \text { and }>2 \\
\text { lobes of }>1 \mathrm{~cm}\end{array}$ & $\begin{array}{l}>4 \mathrm{~cm} \text { with } \\
\text { a folded angle } \\
>100 \text { degrees }\end{array}$ & $\begin{array}{l}<4 \mathrm{~cm} \text { without } \\
\text { any forked lobes }\end{array}$ \\
\hline Description & $\begin{array}{l}\text { Dominant lobe that } \\
\text { presents with an } \\
\text { obvious bend in its } \\
\text { proximal or middle } \\
\text { part, folding back } \\
\text { on itself at some } \\
\text { distance from } \\
\text { the gap }\end{array}$ & $\begin{array}{l}\text { Dominant central } \\
\text { lobe and secondary } \\
\text { lobes arise from it } \\
\text { superiorly and } \\
\text { inferiorly }\end{array}$ & $\begin{array}{l}\text { Dominant lobe } \\
\text { as the primary } \\
\text { structure and there } \\
\text { are variations in the } \\
\text { location and number } \\
\text { of secondary or } \\
\text { even tertiary lobes }\end{array}$ & $\begin{array}{l}\text { More complex internal } \\
\text { characteristics, a varying } \\
\text { number of lobes with } \\
\text { lack of a dominant lobe, } \\
\text { and a more irregular } \\
\text { shape of the gap }\end{array}$ \\
\hline
\end{tabular}

\section{Devices for percutaneous LAAO}

Several devices have been proposed to achieve LAAO: PLAATO, WATCHMAN, Amplatzer Cardiac Plug, Amplatzer Cardiac Plug 2, Amplatzer Amulet, LARIAT, Wavecrest, Lambre, AtriClip Flex Device and Cardia Ultraseal.

The first percutaneous LAA occluder was the Percutaneous Left Atrial Appendage Transcatheter Occlusion (PLAATO) device. Such devices represent a variety of designs and thus offer uniquely different approaches to the mechanical closure of LAA. The PLAATO system was designed as a selfexpanding nitinol cage covered with an expanded membrane to be delivered via a venous access and transseptal crossing into the left atrium. The first human percutaneous LAAO with the use of the PLAATO system was performed by Sievert and Lesh in 2001 [20]. The PLAATO device was with- drawn from the market in 2006 despite favourable preliminary results in terms of safety and efficacy.

The second device developed was the WATCHMAN, which uses a semi-spherical nitinol frame partially coated with a polyethylene terephthalate membrane to block thrombus embolization while providing a scaffold over which endothelialization can occur. The fully repositionable device is available in five sizes, ranging from $21 \mathrm{~mm}$ to $33 \mathrm{~mm}$, in order to accommodate varying LAA anatomies and sizes.

The Amplatzer Cardiac Plug (ACP) and the second-generation ACP2 or Amplatzer Amulet involve similar implantation techniques. These devices consist of a nitinol mesh attached by a waist to an anchoring lobe surrounded by six stabilizing wires. The ACP is available in eight sizes allowing correct accommodation to individual LAA anatomies. 
The LARIAT suture delivery device combines an epicardial and transcatheter endocardial approach. The LAA is entered using a transseptal approach and a magnetic tipped wire is placed at the tip of the LAA. A second magnetic wire is advanced through the pericardial space to the epicardial surface apposing the tip of the LAA. When the two magnetic wires are apposed, a suture can be guided over that rail and around the LAA. This device has a unique advantage in patients with paroxysmal $\mathrm{AF}$, combining anatomical and electrophysiological LAA ligation, excluding a potential source for $\mathrm{AF}$ initiation.

The Cardia Ultraseal LAA closure device is a newly designed device that represents a novel approach to LAAO. The device is constructed with a nitinol frame to be soft and flexible. It is available in nine different bulb sizes (16-34 mm). This device has a unique next-generation design which combines the advantages of a distal anchoring bulb with the proven performance of a proximal sail to close the LAA orifice. These two components are connected with a dual articulating joint allowing the device to conform naturally to the most sinuous of LAA anatomies.

Nowadays, three devices, WATCHMAN (the most widely investigated), Amplatzer Amulet, and ACP 1 are currently the most widely used occluders [16].

\section{Efficacy of percutaneous LAAO in clinical study}

Since the first percutaneous LAAO in 2002 many studies have investigated both safety and efficacy of this therapy using different closure devices. Only one device (WATCHMAN) has been compared with VKA therapy in randomized trials PROTECT-AF (Watchman Left Atrial Appendage System for Embolic Protection in Patients With AF trial) and PREVAIL (Prospective Randomized Evaluation of the Watchman LAA Closure Device In Patients with AF Versus Long Term Warfarin Therapy trial). The PROTECT-AF trial was the first large randomized clinical trial to test this device [21]. The study evaluated 707 patients with nonvalvular $\mathrm{AF}$ who were randomly assigned at a 1:2 ratio to either long-term warfarin with INR 2.0-3.0 or the device therapy. The mean $\mathrm{CHADS}_{2}$ scores in the device and warfarin groups were 2.2 and 2.3 , respectively. The device was placed successfully in $91 \%$ patients. After a mean follow-up of 18 months (1.065 patient-years), the primary efficacy (stroke, systemic embolism and cardiovascular death) event rate was similar in both groups (3.0 vs. 4.9 events per 100 patient-years). The PROTECT-AF study successfully demonstrated the non-inferiority of the WATCHMAN device compared with standard warfarin therapy [21]. A sub-study of the PROTECT-AF study, assessing quality-oflife parameters in 547 patients (361 device and 186 warfarin patients) showed that patients who underwent LAAO had favourable changes in the quality of life at 12 months compared to patients treated with warfarin [22]. A post-hoc analysis of the PROTECT-AF and Continuous Access Protocol (CAP) registry assessed the net clinical benefit of LAAO, combining the rates of thromboembolism, intracranial hemorrhage, major adverse events and death for an objective comparison between LAA device closure vs. anticoagulation in patients with AF [24]. The long-term follow-up data of the PROTECT-AF trial were published in 2014. With a mean follow-up of 3.8 years or 2.621 patientyears, the primary efficacy event rate (combined end-point of all strokes, cardiovascular or unexplained death and systemic embolism) was lower in the WATCHMAN group (2.3\%) than in controls $(3.8 \%)$, which is a $40 \%$ relative risk (RR) reduction, with a $96 \%$ posterior probability of superiority [24].

In the PREVAIL study, 407 patients with AF were randomly assigned at a $2: 1$ ratio either to undergo implantation of the WATCHMAN device or to continue conventional warfarin therapy alone. Due to a low rate of stroke in the control arm, PREVAIL did not achieve non-inferiority for its primary efficacy outcome [25].

Data on the effectiveness of LAAO for stroke prevention were confirmed in a patient-level meta-analysis of the two trials and their associated registries (PROTECT-AF, PREVAIL, CAP, CAP 2) [26]. This meta-analysis included 2,406 patients with 5,931 patient-years. With a mean follow-up of 2.69 years, patients receiving LAAO with the WATCHMAN device had significantly lower rates of hemorrhagic stroke $(0.15$ vs. 0.96 events $/ 100$ patient-years; HR $=0.22$; $\mathrm{p}<0.004)$, cardiovascular/unexplained death (1.1 vs. 2.3 events $/ 100$ patient-years; HR $=0.48$; $\mathrm{p}<0.006)$ and nonprocedural bleeding $(6.0 \%$ vs. $11.3 \%$; $\mathrm{HR}=0.51$; $\mathrm{p}<0.006)$ compared with warfarin. All-cause stroke or systemic embolism was similar in both groups (1.75 vs. 1.87 events/100 patient-years; $\mathrm{HR}=1.02 ; 95 \%$ CI $0.62-1.7 ; \mathrm{p}<0.94)$. There were more ischemic strokes in the device group ( 1.6 vs. 0.9 and 0.2 vs. 1.0 events/ 100 patient-years; $\mathrm{HR}=1.95$ and 0.22 , respectively; $\mathrm{p}<0.05$ and 0.004 , respectively) [26]. It should be noted that the LAAO therapy provides similar benefits as warfarin 
for the composite efficacy endpoint of stroke, systemic embolism or CV death. The pathophysiology of stroke was significantly different in both groups. More warfarin patients were experiencing hemorrhagic strokes and more device patients were experiencing ischemic strokes. Compared to the long-term warfarin therapy, patients randomized to LAAO have a significant improvement in survival, especially as regards CV death [26].

Sabiniewicz et al. [27] presented their first-inhuman original experience with the newly designed Cardia Ultraseal device. Six patients aged from 64 to 70 years (mean 72.8 years) were selected for LAAO. The main indications for LAAO were gastrointestinal bleeding and nose bleeding. Mean HAS-BLED and $\mathrm{CHA}_{2} \mathrm{DS}_{2}$ VASc scale was 3.8 for both. In 5 patients, the Cardia Ultraseal LAA device was implanted without any complications. In 1 patient the anatomy of the LAA and surrounding structures was not suitable for device implantation and the procedure was discontinued. At a 1-month follow-up, the position of all devices on a TEE examination was optimal. There was no thrombus formation and no residual leak, and all LAAs were completely occluded [27]. The LAA closure may also be performed using surgical methods: intraoperative and thoracoscopic. Table 3 presents a review of the published data on percutaneous LAAO [21, 25, 28-35].

\section{Safety of percutaneous LAAO}

Left atrial appendage closure is a complicated procedure requiring the insertion of large catheters through the groin, transseptal puncture and catheter navigation within both left atrium and LAA. Complications such as thrombus formation, bleeding, stroke, vascular rupture, myocardial infarction and pericardial effusion may occur at each stage of the procedure.

In the PROTECT-AF study, the most common safety endpoint in the intervention group was cardiac tamponade requiring percutaneous or surgical drainage ( $4.8 \%$ patients). Other safety endpoints included periprocedural strokes $(1.1 \%)$ and implant embolization $(0.6 \%)$. Overall, major complications occurred in $6 \%$ of patients undergoing invasive treatment in the PROTECT-AF study [24]. Over the last months, the clinical data from the large real-world EWOLUTION registry with 1021 patients subsequent to WATCHMAN implantation have been published. Patients in this registry were at a high risk of stroke (average $\mathrm{CHADS}_{2}$ score: 2.8 and a $\mathrm{CHA}_{2} \mathrm{DS}_{2}$ VASc score: 4.5 ) but also had a moderate-to-high risk of bleeding. Nearly one-third of all subjects had a history of major bleeding (31.2\%). In $98.5 \%$ of patients, the device was successfully deployed with no flow or minimal residual flow (defined as $<5 \mathrm{~mm}$ assessed via periprocedural TEE) achieved in $99.3 \%$ of implanted patients. In this registry, the safety profile of the WATCHMAN device was more favorable, when compared to previous studies. Device or procedure-related serious adverse event rates on day 92 were similar in patients treated with warfarin or dual antiplatelet therapy (DAPT) (2.6\% vs. $4.8 \%$, respectively). The most common serious adverse event that occurred within 30 days of the procedure was major bleeding requiring transfusion. In particular, the rate of procedural/device-related strokes, with a rate of $0.1 \%$ in that study, was substantially lower compared to the $0.9 \%$ in the PROTECT-AF and $0.4 \%$ in PREVAIL studies [36]. The success of the procedure significantly depends on the experience of the operator performing LAAO. This was confirmed in the PROTECT-AF study. The incidence of severe pericardial effusion was related to both centre and operator experience, being $50 \%$ higher in newly initiated sites. Moreover, the data derived from the CAP registry performed in the centres participating in the PROTECT-AF study after the study was closed, proved the cause-effect relationship between level of experience and risk of complication [37].

\section{Anticoagulant/antiplatelet therapy after LAAO}

The risk of thrombus formation on the surface of devices implanted to eliminate the LAA is high, and it is necessary to use anticoagulant or antiplatelet therapy until the end epithelialization. Unfortunately, neither the type of therapy nor the duration of treatment has been clearly defined. In the PROTECT-AF study, patients allocated to the device group were treated post procedure with warfarin for 45 days to facilitate device endothelialisation. Warfarin was discontinued if TEE at 45 days after LAAO showed no complications. After discontinuation of warfarin, clopidogrel and aspirin were given over 6 months of follow-up. After this period, aspirin alone was continued. The control group received warfarin with INR 2.0-3.0, which was accomplished only over two-thirds of the time despite close INR monitoring [21]. It is important to remember that this study included patients with indications to anticoagulation treatment and no contraindications to anticoagulation treatment according to European Society of Cardiology (ESC) guidelines [10]. In the ASAP study, patients after 
Table 3. Review of published data on percutaneous left atrial appendage occlusion.

\begin{tabular}{|c|c|c|c|c|c|}
\hline Device & Trial & $\begin{array}{l}\text { Number } \\
\text { of patients }\end{array}$ & $\begin{array}{l}\text { Successful } \\
\text { implant }\end{array}$ & Outcomes & $\begin{array}{l}\text { Antithrombotic } \\
\text { therapy after } \\
\text { implantation }\end{array}$ \\
\hline \multirow[t]{9}{*}{ WATCHMAN } & \multirow[t]{4}{*}{$\begin{array}{l}\text { PROTECT-AF } \\
{[21]}\end{array}$} & \multirow[t]{4}{*}{707} & \multirow[t]{4}{*}{$90.9 \%$} & $\begin{array}{l}\text { Device group vs. VKA group: } \\
\text { - Ischemic CVA: } \\
9(5.2 \%) \text { vs. } 6(4.1 \%)\end{array}$ & \multirow[t]{4}{*}{$\begin{array}{l}45 \text { days of VKA } \\
\text { followed by } 4.5 \text { months } \\
\text { of clopidogrel and } \\
\text { lifelong aspirin }\end{array}$} \\
\hline & & & & $\begin{array}{l}\text { - Hemorrhagic stroke: } \\
3(0.6 \%) \text { vs. } 10(4.1 \%)\end{array}$ & \\
\hline & & & & $\begin{array}{l}\text { - Systemic embolization: } \\
3(0.6 \%) \text { vs. } 0(0 \%)\end{array}$ & \\
\hline & & & & $\begin{array}{l}\text { - All-cause mortality: } \\
57(12.3 \%) \text { vs. } 44(18 \%)\end{array}$ & \\
\hline & \multirow[t]{4}{*}{ PREVAIL [25] } & \multirow[t]{4}{*}{407} & \multirow[t]{4}{*}{$95.1 \%$} & $\begin{array}{l}\text { Device group vs. VKA group: } \\
\text { - Ischemic CVA: } \\
5(1.9 \%) \text { vs. } 1(0.7 \%)\end{array}$ & \multirow{4}{*}{$\begin{array}{l}45 \text { days of VKA } \\
\text { followed by } 4.5 \text { months } \\
\text { of clopidogrel and } \\
\text { lifelong aspirin }\end{array}$} \\
\hline & & & & $\begin{array}{l}\text { - Hemorrhagic stroke: } \\
1(0.4 \%) \text { vs. } 0(0 \%)\end{array}$ & \\
\hline & & & & $\begin{array}{l}\text { - Systemic embolization: } \\
1(0.4 \%) \text { vs. } 0(0 \%)\end{array}$ & \\
\hline & & & & $\begin{array}{l}\text { - Death (cardiac/unexplained): } \\
7(2.6 \%) \text { vs. } 3(2.2 \%)\end{array}$ & \\
\hline & ASAP [28] & 150 & $94.7 \%$ & $\begin{array}{l}\text { Ischemic CVA: } 3(1.7 \%) \\
\text { Hemorrhagic stroke: } 1(0.6 \%) \\
\text { All-cause mortality: } 9(5 \%)\end{array}$ & $\begin{array}{l}45 \text { days of VKA followed } \\
\text { by } 4.5 \text { months of } \\
\text { clopidogrel and lifelong } \\
\text { aspirin }\end{array}$ \\
\hline \multirow[t]{6}{*}{ AMPLATZER } & $\begin{array}{l}\text { Tzikas } \\
\text { et al. [29] }\end{array}$ & 1047 & $97.3 \%$ & $\begin{array}{l}\text { Stroke (type unspecified): } 9 \% \\
\text { TIA: } 9 \% \\
\text { Systemic embolism: } 31(2.3 \%) \\
\text { All-cause mortality: } 63(4.3 \%) \\
\text { Cardiac mortality: } 17(1.6 \%)\end{array}$ & $\begin{array}{l}\text { Aspirin/clopidogrel for } \\
1-3 \text { months followed } \\
\text { by } \geq 3 \text { months aspirin }\end{array}$ \\
\hline & $\begin{array}{l}\text { Kefer } \\
\text { et al. [30] }\end{array}$ & 90 & $98 \%$ & $\begin{array}{l}\text { Stroke (type unspecified): } \\
2(2.2 \%) \\
\text { Myocardial infarction: } 1(1.1 \%) \\
\text { All-cause mortality: } 4(4.4 \%)\end{array}$ & $\begin{array}{l}\text { Aspirin/clopidogrel for } \\
1 \text { month followed } \\
\text { by lifelong aspirin }\end{array}$ \\
\hline & $\begin{array}{l}\text { Urena } \\
\text { et al. [31] }\end{array}$ & 52 & $98.1 \%$ & $\begin{array}{l}\text { Stroke }(1.7 \text { years): } 1.9 \% \\
\text { Systemic embolism: } \\
\text { (1.7 years): } 0 \%\end{array}$ & $\begin{array}{l}\text { Aspirin plus clopidogrel, } \\
\text { or aspirin or clopidogrel } \\
\text { alone for } 30-180 \text { days } \\
\text { followed by single } \\
\text { antiplatelet therapy }\end{array}$ \\
\hline & $\mathrm{ACP}[32]$ & 35 & $97.1 \%$ & Stroke: $0(0 \%)$ & Aspirin/clopidogrel for \\
\hline & & & & Cardiac mortality: $0(0 \%)$ & 3 months followed \\
\hline & & & & All-cause mortality: 3 (8.6\%) & by aspirin for 6 months \\
\hline \multirow[t]{6}{*}{ LARIAT } & \multirow{4}{*}{$\begin{array}{l}\text { Price } \\
\text { et al. [33] }\end{array}$} & \multirow[t]{4}{*}{154} & \multirow[t]{4}{*}{$94 \%$} & Cardiac death: $2(1.3 \%)$ & Aspirin: 47 (31\%) \\
\hline & & & & All-cause mortality: $3(1.9 \%)$ & DAPT: $37(24 \%)$ \\
\hline & & & & $\begin{array}{l}\text { Stroke (unspecified type): } \\
2(1.3 \%)\end{array}$ & $\begin{array}{l}\text { No antithrombotic } \\
\text { therapy: } 29(19 \%)\end{array}$ \\
\hline & & & & & Clopidogrel: $11(7 \%)$ \\
\hline & $\begin{array}{l}\text { Bartus } \\
\text { et al. [34] }\end{array}$ & 89 & $96 \%$ & Not available & $\begin{array}{l}\mathrm{CHADS}_{2} \leq 1 \text { : aspirin } \\
\mathrm{CHADS}_{2} \geq 2: \text { VKA }\end{array}$ \\
\hline & $\begin{array}{l}\text { Miller et al. } \\
{[35]}\end{array}$ & 41 & $93 \%$ & Not available & $\begin{array}{l}\text { Aspirin: } 19(46 \%) \\
\text { Clopidogrel: } 3(7 \%) \\
\text { VKA: } 8(20 \%) \\
\text { Dabigatran: } 3(7 \%) \\
\text { Rivaroxaban: } 1(2 \%)\end{array}$ \\
\hline
\end{tabular}

CVA — cerebrovascular accident; VKA — vitamin K antagonist; TIA — transient ischemic attack; DAPT — dual antiplatelet therapy 
WATCHMAN implantation were treated only with clopidogrel at a dose of $75 \mathrm{mg}$ and aspirin at a dose of $75 \mathrm{mg}$ over a 6 months period, and then only with aspirin [37]. The frequency of thrombus occurrence was comparable in patients in the ASAP study (4\%) and in the PROTECT-AF study $(4.2 \%)$ [21, 37]. In the EWOLUTION registry, $6 \%$ of patients following WATCHMAN implantation received no anticoagulation, $27 \%$ received oral anticoagulation (16\% warfarin and $11 \%$ novel oral anticoagulants, NOAC), $60 \%$ received DAPT and $7 \%$ of patients were on single antiplatelet therapy [36]. There were no indications of anticoagulant treatment following Amplatzer device implantation. The producer of the device recommended DAPT for 1 month and only aspirin for the next 5 months. According to ESC guidelines, after surgical occlusion or exclusion of the LAA, it is recommended to continue anticoagulation for stroke prevention in high risk patients with $\mathrm{AF}$ [10].

\section{Left atrial appendage occlusion: New perspectives, unresolved problems and gaps in evidence}

The first 45 days after implantation of the device are a critical transition period, because after this time a complete endothelialization of the device is expected. An incomplete endothelialization, however, is associated with a risk of thrombus formation. According to the manufacturer's recommendation, warfarin is therefore recommended during the first 45 days after device implantation. There are data suggesting that DAPT is also reasonable in patients with absolute contraindications to warfarin. New oral anticoagulants are increasingly being used instead of warfarin. Data on the use of NOAC in patients after LAAO are scarce. A pilot study evaluated 45 patients after implantation of an LAA occlusion device (WATCHMAN) [38]. Following implantation, individualized drug therapy was instituted. Patients without prior DAPT or contraindications to OAC received NOAC (dabigatran or rivaroxaban) for $\geq 45$ days according to the operator's decision. After 45 days, OAC was usually stopped and clopidogrel $(75 \mathrm{mg} / \mathrm{d}$.) and aspirin $(100 \mathrm{mg} / \mathrm{d}$.) was instituted for 6 months following WATCHMAN implantation. After that, clopidogrel was stopped and aspirin monotherapy was continued. After implantation, 27 (60\%) patients received DAPT (aspirin $100 \mathrm{mg} / \mathrm{d}$. and clopidogrel $75 \mathrm{mg} / \mathrm{d}$.) for $\geq 6$ months and this scheme is now widely used after WATCHMAN implantation. Eighteen (40\%) patients received NOAC.
Dabigatran $(2 \times 110 \mathrm{mg} / \mathrm{d}$. $)$ was administered in 16 patients and rivaroxaban $(1 \times 20 \mathrm{mg} / \mathrm{d}$. $)$ in $2 \mathrm{pa}$ tients for $\geq 45$ days. After this time, TEE revealed no abnormal thrombus formation.

During a follow-up of $417 \pm 323$ days, 7 patients died. No stroke or transient ischemic attack occurred. Non-fatal myocardial infarction occurred in 1 patient. There was a non-significant trend for a lower all-cause mortality $(\mathrm{p}=0.159)$ and for the occurrence of major adverse cardiac and cerebrovascular events $(\mathrm{p}=0.096)$ in the NOAC group, compared to the DAPT group. A total of 6 patients suffered from a major bleeding (NOAC group, $\mathrm{n}=3$; DAPT group, $\mathrm{n}=3$ ). There was no significant difference in the frequency of major bleeding between the groups. The presented study suggests that NOAC therapy within the first 45 days after WATCHMAN implantation was at least as safe and as effective as therapy with aspirin $(100 \mathrm{mg} / \mathrm{d}$.) and clopidogrel. There was no direct comparison between different ways of $\mathrm{OAC}$, and especially between NOAC and warfarin in patients after LAAO.

The presence of a thrombus in the LAA is considered as a contraindication to percutaneous LAAO, as manipulation of catheters, guidewires, sheaths or devices in the LAA may lead to systemic embolization. In patients with real contraindications to OAC, there is no alternative option for decreasing the high risk of an embolic event. The prevalence of LAA thrombi in patients with an LAAO indication is difficult to evaluate as LAA thrombi or dense spontaneous contrast on TEE are considered as exclusion criteria in the majority of studies. There is no consensus for patients in whom a LAA thrombus is present and OAC is contraindicated.

An incomplete LAAO with peridevice leaks may allow thrombus embolization. Detection of peridevice leaks is challenging, and variable leak frequencies ranging from $8.2 \%$ to $62 \%$ have been reported after Amplatzer Cardiac Plug implantation on TEE or computed tomography imaging $[39,40]$. Neuzner et al. [41] presented that the late decompression of the ACP lobe was observed in $61 \%$ of patients, leading to a complete loss in device compression in $27 \%$. This observation may be the rationale for a higher degree of ACP oversizing during implantation. There are a few reports available showing an effective implantation of occluders in patients with thrombi in LAA. Aytemir et al. [42] described the first case of LAAO with the Amplatzer Amulet device in a patient who had a thrombus in LAA. The final result was excellent without a significant residual leak, pericardial effu- 
sion or embolic complications. Bokhari et al. [43] described the case of woman who was found to have LAA thrombus persistence despite dabigatran anticoagulation; she underwent LAA mechanical thrombectomy and subsequent successful LAAO with embolic neuroprotection. Meincke et al. [44] published two cases of successful LAAO using the WATCHMAN device and similar cerebral protection systems in patients with a known thrombus within LAA. Jalal et al. [45] published a case series of 3 patients known to have thrombi within LAA, in whom a successful percutaneous LAA closure was performed using a simplified implantation technique. No early procedural complications occurred in these patients. It seems that LAAO may be alternative option for patients with LAA thrombi and contraindications to OAC.

Despite several years of experience with different LAA closure systems, this form of stroke prevention in patients with $\mathrm{AF}$ and high risk of stroke has not become widely adopted. Issues which remain unresolved include a lack of data on optimal patient selection, risk of complications, and the possibility of incomplete LAA closure. Other important unresolved issues are the lack of recommendations for the time of antiplatelet therapy, the lack of direct data comparing LAA occlusion with NOAC therapy and of data which compare devices, implanting strategies and therapies following implantation.

\section{Conflict of interest: None declared}

\section{References}

1. Stewart S, Hart CL, Hole DJ, et al. Population prevalence, incidence, and predictors of atrial fibrillation in the Renfrew/ /Paisley study. Heart. 2001; 86(5): 516-521, indexed in Pubmed: 11602543 .

2. Lloyd-Jones D, Adams R, Carnethon M, et al. American Heart Association Statistics Committee and Stroke Statistics Subcommittee, American Heart Association Statistics Committee and Stroke Statistics Subcommittee. Heart disease and stroke statistics - 2009 update: a report from the American Heart Association Statistics Committee and Stroke Statistics Subcommittee. Circulation. 2009; 119(3): e21-e181, doi: 10.1161/CIRCULATIONAHA.108.191261, indexed in Pubmed: 19075105.

3. Wolf PA, Abbott RD, Kannel WB. Atrial fibrillation as an independent risk factor for stroke: the Framingham Study. Stroke. 1991; 22(8): 983-988, indexed in Pubmed: 1866765.

4. Go AS, Hylek EM, Phillips KA, et al. Warfarin use among ambulatory patients with nonvalvular atrial fibrillation: the anticoagulation and risk factors in atrial fibrillation (ATRIA) study. Ann Intern Med. 1999; 131(12): 927-934, indexed in Pubmed: 10610643 .

5. Tu HTH, Campbell BCV, Christensen S, et al. Echoplanar Imaging Thrombolytic Evaluation Trial (EPITHET) Investigators. Pathophysiological determinants of worse stroke outcome in atrial fibrillation. Cerebrovasc Dis. 2010; 30(4): 389-395, doi: 10.1159/000316886, indexed in Pubmed: 20693794.

6. Lin HJ, Wolf PA, Kelly-Hayes M, et al. Stroke severity in atrial fibrillation. The Framingham Study. Stroke. 1996; 27(10): 1760-1764, indexed in Pubmed: 8841325.

7. Hart RG, Pearce LA, Aguilar MI. Meta-analysis: antithrombotic therapy to prevent stroke in patients who have nonvalvular atrial fibrillation. Ann Intern Med. 2007; 146(12): 857-867, indexed in Pubmed: 17577005.

8. Waldo AL, Becker RC, Tapson VF, et al. NABOR Steering Committee. Hospitalized patients with atrial fibrillation and a high risk of stroke are not being provided with adequate anticoagulation. J Am Coll Cardiol. 2005; 46(9): 1729-1736, doi: 10.1016/j. jacc.2005.06.077, indexed in Pubmed: 16256877.

9. Ruff CT, Giugliano RP, Braunwald E, et al. Comparison of the efficacy and safety of new oral anticoagulants with warfarin in patients with atrial fibrillation: a meta-analysis of randomised trials. Lancet. 2014; 383(9921): 955-962, doi: 10.1016/S01406736(13)62343-0, indexed in Pubmed: 24315724.

10. Kirchhof P, Benussi S, Kotecha D, et al. 2016 ESC Guidelines for the management of atrial fibrillation developed in collaboration with EACTS. Europace. 2016; 18(11): 1609-1678, doi: 10.1093/ /europace/euw295, indexed in Pubmed: 27567465.

11. Aberg H. Atrial fibrillation. I. A study of atrial thrombosis and systemic embolism in a necropsy material. Acta Med Scand. 1969; 185(5): 373-379, indexed in Pubmed: 5808636.

12. Stoddard MF, Dawkins PR, Prince CR, et al. Left atrial appendage thrombus is not uncommon in patients with acute atrial fibrillation and a recent embolic event: A transesophageal echocardiographics tudy. J Am Coll Cardiol. 1995; 25(2): 452-459, doi: 10.1016/0735-1097(94)00396-8.

13. Wunderlich NC, Beigel R, Swaans MJ, et al. Percutaneous interventions for left atrial appendage exclusion: options, assessment, and imaging using 2D and 3D echocardiography. JACC Cardiovasc Imaging. 2015; 8(4): 472-488, doi: 10.1016/j.jcmg.2015.02.002, indexed in Pubmed: 25882576.

14. Beigel R, Wunderlich NC, Kar S, et al. The evolution of percutaneous mitral valve repair therapy: lessons learned and implications for patient selection. J Am Coll Cardiol. 2014; 64(24): 2688-2700, doi: 10.1016/j.jacc.2014.08.049, indexed in Pubmed: 25524345 .

15. Kimura T, Takatsuki S, Inagawa K, et al. Anatomical characteristics of the left atrial appendage in cardiogenic stroke with low CHADS2 scores. Heart Rhythm. 2013; 10(6): 921-925, doi: 10.1016/j.hrthm.2013.01.036, indexed in Pubmed: 23384894.

16. Wąsek WC, Rosso R. Transcatheter left atrial appendage occlusion in the prevention of stroke and death in patients with atrial fibrillation. Kardiol Pol. 2014; 72(11): 1127-1134, doi: 10.5603/ KP.a2014.0130, indexed in Pubmed: 25522752.

17. Veinot JP, Harrity PJ, Gentile F, et al. Anatomy of the normal left atrial appendage: a quantitative study of age-related changes in 500 autopsy hearts: implications for echocardiographic examination. Circulation. 1997; 96(9): 3112-3115, indexed in Pubmed: 9386182.

18. Yamamoto M, Seo Y, Kawamatsu N, et al. Complex left atrial appendage morphology and left atrial appendage thrombus formation in patients with atrial fibrillation. Circ Cardiovasc Imaging. 2014; 7(2): 337-343, doi: 10.1161/CIRCIMAGING.113.001317, indexed in Pubmed: 24523417.

19. Nucifora G, Faletra FF, Regoli F, et al. Evaluation of the left atrial appendage with real-time 3-dimensional transesophageal echocardiography: implications for catheter-based left atrial appendage closure. Circ Cardiovasc Imaging. 2011; 4(5): 514-523, doi: 10.1161/CIRCIMAGING.111.963892, indexed in Pubmed: 21737601 . 
20. Sievert H, Lesh MD, Trepels T, et al. Percutaneous left atrial appendage transcatheter occlusion to prevent stroke in high-risk patients with atrial fibrillation: early clinical experience. Circulation. 2002; 105(16): 1887-1889, indexed in Pubmed: 11997272.

21. Holmes DR, Reddy VY, Turi ZG, et al. PROTECT AF Investigators. Percutaneous closure of the left atrial appendage versus warfarin therapy for prevention of stroke in patients with atrial fibrillation: a randomised non-inferiority trial. Lancet. 2009; 374(9689): 534-542, doi: 10.1016/S0140-6736(09)61343-X, indexed in Pubmed: 19683639.

22. Alli O, Doshi S, Kar S, et al. Quality of life assessment in the randomized PROTECT AF (Percutaneous Closure of the Left Atrial Appendage Versus Warfarin Therapy for Prevention of Stroke in Patients With Atrial Fibrillation) trial of patients at risk for stroke with nonvalvular atrial fibrillation. J Am Coll Cardiol. 2013; 61(17): 1790-1798, doi: 10.1016/j.jacc.2013.01.061, indexed in Pubmed: 23500276.

23. Gangireddy SR, Halperin JL, Fuster V, et al. Percutaneous left atrial appendage closure for stroke prevention in patients with atrial fibrillation: an assessment of net clinical benefit. Eur Heart J. 2012; 33(21): 2700-2708, doi: 10.1093/eurheartj/ehs292, indexed in Pubmed: 23008509.

24. Reddy VY, Sievert H, Halperin J, et al. PROTECT AF Steering Committee and Investigators. Percutaneous left atrial appendage closure vs warfarin for atrial fibrillation: a randomized clinical trial. JAMA. 2014; 312(19): 1988-1998, doi: 10.1001/ /jama.2014.15192, indexed in Pubmed: 25399274.

25. Holmes DR, Kar S, Price MJ, et al. Prospective randomized evaluation of the Watchman left atrial appendage closure device in patients with atrial fibrillation versus long-term warfarin therapy: the PREVAIL trial. J Am Coll Cardiol. 2014; 64(1): 1-12, doi: 10.1016/j.jacc.2014.04.029, indexed in Pubmed: 24998121.

26. Holmes DR, Doshi SK, Kar S, et al. Left atrial appendage closure as an alternative to warfarin for stroke prevention in atrial fibrillation: a patient-level meta-analysis. J Am Coll Cardiol. 2015; 65(24): 2614-2623, doi: 10.1016/j.jacc.2015.04.025, indexed in Pubmed: 26088300.

27. Sabiniewicz R, Hiczkiewicz J, Wańczura P, et al. First-in-human experience with the Cardia Ultraseal left atrial appendage closure device: The feasibility study. Cardiol J. 2016; 23(6): 652-654, doi: 10.5603/CJ.2016.0106, indexed in Pubmed: 27976795.

28. Reddy VY, Möbius-Winkler S, Miller MA, et al. Left atrial appendage closure with the Watchman device in patients with a contraindication for oral anticoagulation: the ASAP study (ASA Plavix Feasibility Study With Watchman Left Atrial Appendage Closure Technology). J Am Coll Cardiol. 2013; 61(25): 2551-2556, doi: 10.1016/j.jacc.2013.03.035, indexed in Pubmed: 23583249.

29. Tzikas A, Shakir S, Gafoor S, et al. Left atrial appendage occlusion for stroke prevention in atrial fibrillation: multicentre experience with the AMPLATZER Cardiac Plug. EuroIntervention. 2016; 11(10): 1170-1179, doi: 10.4244/EIJY15M01_06, indexed in Pubmed: 25604089.

30. Kefer J, Vermeersch P, Budts W, et al. Transcatheter left atrial appendage closure for stroke prevention in atrial fibrillation with Amplatzer cardiac plug: the Belgian Registry. Acta Cardiol. 2013; 68(6): 551-558, doi: 10.2143/AC.68.6.8000001, indexed in Pubmed: 24579432.

31. Urena M, Rodés-Cabau J, Freixa X, et al. Percutaneous left atrial appendage closure with the AMPLATZER cardiac plug device in patients with nonvalvular atrial fibrillation and contraindications to anticoagulation therapy. J Am Coll Cardiol. 2013; 62(2): 96-102, doi: 10.1016/j.jacc.2013.02.089, indexed in Pubmed: 23665098.

32. López-Mínguez JR, Eldoayen-Gragera J, González-Fernández R, et al. Immediate and one-year results in 35 consecutive patients after closure of left atrial appendage with the Amplatzer cardiac plug. Rev Esp Cardiol (Engl Ed). 2013; 66(2): 90-97, doi: 10.1016/j.rec.2012.04.017, indexed in Pubmed: 24775381.

33. Price MJ, Gibson DN, Yakubov SJ, et al. Early safety and efficacy of percutaneous left atrial appendage suture ligation: results from the U.S. transcatheter LAA ligation consortium. J Am Coll Cardiol. 2014; 64(6): 565-572, doi: 10.1016/j.jacc.2014.03.057, indexed in Pubmed: 25104525.

34. Bartus K, Han FT, Bednarek J, et al. Percutaneous left atrial appendage suture ligation using the LARIAT device in patients with atrial fibrillation: initial clinical experience. J Am Coll Cardiol. 2013; 62(2): 108-118, doi: 10.1016/j.jacc.2012.06.046, indexed in Pubmed: 23062528.

35. Miller MA, Gangireddy SR, Doshi SK, et al. Multicenter study on acute and long-term safety and efficacy of percutaneous left atrial appendage closure using an epicardial suture snaring device. Heart Rhythm. 2014; 11(11): 1853-1859, doi: 10.1016/j. hrthm.2014.07.032, indexed in Pubmed: 25068574.

36. Boersma LVA, Schmidt B, Betts TR, et al. EWOLUTION investigators. Implant success and safety of left atrial appendage closure with the WATCHMAN device: peri-procedural outcomes from the EWOLUTION registry. Eur Heart J. 2016; 37(31): 2465-2474, doi: 10.1093/eurheartj/ehv730, indexed in Pubmed: 26822918.

37. Reddy VY, Holmes D, Doshi SK, et al. Safety of percutaneous left atrial appendage closure: results from the Watchman Left Atrial Appendage System for Embolic Protection in Patients with AF (PROTECT AF) clinical trial and the Continued Access Registry. Circulation. 2011; 123(4): 417-424, doi: 10.1161/CIRCULATIONAHA.110.976449, indexed in Pubmed: 21242484.

38. Bösche LI, Afshari F, Schöne D, et al. Initial experience with novel oral anticoagulants during the first 45 days after left atrial appendage closure with the Watchman device. Clin Cardiol. 2015; 38(12): 720-724, doi: 10.1002/clc.22478, indexed in Pubmed: 26467851.

39. Jaguszewski M, Manes C, Puippe G, et al. Cardiac CT and echocardiographic evaluation of peri-device flow after percutaneous left atrial appendage closure using the AMPLATZER cardiac plug device. Catheter Cardiovasc Interv. 2015; 85(2): 306-312, doi: 10.1002/ccd.25667, indexed in Pubmed: 25205611.

40. López Mínguez JR, Asensio JM, Gragera JE, et al. Two-year clinical outcome from the Iberian registry patients after left atrial appendage closure. Heart. 2015; 101(11): 877-883, doi: 10.1136/ /heartjnl-2014-306332, indexed in Pubmed: 25573984.

41. Neuzner J, Dietze T, Paliege R, et al. Left atrial appendage closure with the Amplatzer ${ }^{\mathrm{TM}}$ Cardiac Plug: Rationale for a higher degree of device oversizing at implantation. Cardiol J, 2015; 22(2): 201-205, doi: 10.5603/CJ.a2014.0063.

42. Aytemir K, Aminian A, Asil S, et al. First case of percutaneous left atrial appendage closure by amulet ${ }^{\mathrm{TM}}$ device in a patient with left atrial appendage thrombus. Int J Cardiol. 2016; 223: 28-30, doi: 10.1016/j.ijcard.2016.08.171, indexed in Pubmed: 27529584.

43. Bokhari SSI, Martinez-Clark P, Zambrano JP, et al. Percutaneous mechanical thrombectomy of left atrial appendage thrombus with bilateral neuro-embolic protection followed by closure of left atrial appendage. EuroIntervention. 2012; 8(3): 408-409, doi: 10.4244/EIJV8I3A61, indexed in Pubmed: 22829514.

44. Meincke F, Kreidel F, von Wedel J, et al. Percutaneous left atrial appendage closure in patients with left atrial appendage thrombus. EuroIntervention. 2015; 10(10): 1208, doi: 10.4244/ /EIJV10I10A199, indexed in Pubmed: 24642583.

45. Jalal Z, Iriart X, Dinet ML, et al. Extending percutaneous left atrial appendage closure indications using the AMPLATZER ${ }^{\text {тм }}$ Cardiac Plug device in patients with persistent left atrial appendage thrombus: The thrombus trapping technique. Arch Cardiovasc Dis. 2016; 109(12): 659-666, doi: 10.1016/j.acvd.2016.02.012, indexed in Pubmed: 27402154. 